\title{
EDUCAÇÃO DO CAMPO E ESCOLA FAMÍLIA AGRÍCOLA DE GOIÁS: O CAMINHAR DA TEIMOSIA DE UM MOVIMENTO SOCIAL EDUCATIVO $^{1}$
}

Claudemiro Godoy do Nascimento*

\section{Resumo}

Este artigo tem por objetivo apresentar a realidade da educação rural em Goiás, no Brasil. Mostra as dificuldades na educação rural e como era 0 ensino da população de camponeses. Então, nós mostraremos as alternativas entre o paradigma de educação urbano e o da educação rural. Nós sabemos porque nossa escola rural, Escola Família Agrícola de Goiás, advém desse movimento social educativo, organizado pela associação de pais.

Palavras-chave: Educação; Zona rural; Pedagogia; Cultura; Memória; Histónia.

\section{Abstract}

This article have the objetive of to present the reality of rural education, in Goiás and in Brasil. It shows the difficulties in rural education and how it has been teaching to peasant population. Then, we will show the alternative paradigm between urban and rural education. We know that the foundation of our rural school, Escola Família Agricola de Goiás, veas from the social educativw moviment that was organized by fathers's association.

Keywords: Education; Rural zone; Pedagogy; Cultural; Memory; History.

\section{Introdução}

O texto aqui exposto tem o objetivo de levantar um debate sobre a situação caótica pela qual vem passando a educação do campo no Brasil e em Goiás. As Escolas Famílias Agrícolas constituem-se como uma proposta alternativa para que esta dura realidade de exclusão, criada a partir das políticas públicas neoliberais, sejam aos poucos amenizadas.

Licenciado em Filosofia pela UCG/IFITEG. Mestrando em Educação/UNICAMP.

E-mail: claugnas@unicamp.br 
Torna-se necessário compreender as representações simbólicas e ideológicas que se formou ao longo dos tempos em relação ao homem e a mulher do campo, menosprezados num processo discriminatório de séculos, ficando submetidos à ideologia de que a educação é desnecessária para quem usa sua força de trabalho na roça, na plantação. Assim, num primeiro momento, busco mostrar alguns problemas que a realidade atual nos apresenta em relação à educação rural no Brasil e em Goiás, sabendo que tal realidade veio se formando nestes 500 anos de desigualdade social e educativa.

Posteriormente, demonstro que a educação do campo está sendo pensada e refletida a partir de educadores comprometidos com a causa de uma educação que se faz nas culturas diversas que existem no Brasil. A educação do campo acontece como espécie de rebeldia, de teimosia dentro da esfera pública, a partir de movimentos sociais educativos ou não, dentre eles, a Escola Família Agrícola de Goiás (EFAGO) e todas as EFAs. Por fim, mostro que a EFAGO, juntamente com outros movimentos, como o MST, a CPT e os povos indígenas são verdadeiros espaços de construção de uma educação do campo, constituindo-se, assim, como movimentos sociais educativos voltados a atender os interesses dos(as) camponeses/as, excluídos/as de serem cidadãos/as, pois a cidadania tão apregoada pelos órgãos públicos educacionais desrespeita o maior tesouro da realidade camponesa, a saber: a cultura que se faz a partir da dialética existente na história e na memória coletiva das comunidades rurais.

\section{A rea lidade da educação rural no Brasil e em Goiás}

O Brasil é um país marcado pela exclusão e desigualdade social. Dentro deste quadro estão inseridos os(as) camponeses/as, considerados como atrasados e para Wanderley (1997) eles são os "fora de lugar" no mundo moderno. São vistos como espécies em extinção, condenados ao desaparecimento por aqueles que fazem parte do modelo de desenvolvimento urbano.

Um grande desafio a ser vencido na realidade social do meio rural são os muitos conceitos que qualificam ou desqualificam os habitantes do campo. Tais conceitos podem ser valorativos ou depreciativos, além de muitos serem pejorativos. Por exemplo: é pejorativo conceber aos camponeses/as os estereótipos de atrasados, preguiçosos, ingênuos e incapazes, porque tal postura só vem demonstrar uma espécie de racismo rural disfarçado e camuflado.

Tais estereótipos são criados pelo ethos da sociedade brasileira em relação ao camponês visto como sendo aquele que pertence ao mundo atrasado. A partir de um estudo fundamental de Martins (1975, p. 04) o camponês 
é visto como o Jeca Tatu que precisa se adequar e se integrar ao sistema social do mundo urbano que hoje é o mercado. Desencadeia-se por meio da relação entre urbano-rural uma situação de dependência e fetiche construída pelas relações políticas e pelo modo de produção ${ }^{3}$. É preciso romper com essa visão unilateral, dicotômica (moderno-atrasado) que gera a dominação do urbano sobre o rural e recriar uma concepção de dependência mútua, onde um não sobrevive sem o outro.

A população rural é vista, conforme dados do IBGE, como uma população condenada ao esquecimento. Com o avanço do capitalismo no campo, subordinadas à lógica do capital, criaram-se três problemas para os(as) camponeses/as: um desenvolvimento desigual, um processo excludente que veio se caracterizar no êxodo rural e, por fim, um modelo de agricultura que produz relações sociais ora atrasadas ora modernas. Este capitalismo voraz e selvagem gerou a concentração da propriedade e da renda, a concentração urbana, o desemprego e a intensificação da violência, além de demarcar 0 urbano como superior ao rural.

A agricultura familiar camponesa foi abandonada, ao longo do século XX, pelas políticas públicas do Estado. A política agrícola do Estado prioriza a agricultura capitalista patronal, baseada na monocultura exportadora que busca atender ao mercado global, marginalizando, por outro lado, a agricultura familiar camponesa destinada à subsistência e ao mercado local.

Segundo Lisita (1992), quando há resistência dos camponeses, estes enfrentam a ira e a violência das velhas oligarquias rurais que mantêm 0 monopólio dos latifúndios improdutivos.

A perspectiva dos camponeses numa visão pessimista seria o desaparecimento, a migração para os grandes centros urbanos ou o reiniciar da luta pela terra; alguns se incorporando ao sistema, assumindo as novas tecnologias, reformando-se com tecnologias alternativas, transformando-se por meio da cooperação agrícola ou reorganizando-se com novas experiências. A perspectiva dos pequenos, ao qual chamo de excluídos/as, pode estar vinculada à agricultura camponesa familiar a partir da criação de alternativas como é o caso das experiências das cooperativas. As cooperativas são uma contribuição especial para o projeto alternativo, pois pode gerar empregos, barateando os alimentos e liberando venda para outros setores da economia, além de melhorar as condições de vida do povo. Para que isso se efetive, é necessária uma inversão política por parte das políticas públicas referentes aos projetos agrários. Nesse sentido, é preciso ver: os camponeses como sujeitos históricos deste projeto de desenvolvimento que buscam na agricultura familiar a base de suas lutas; políticas voltadas para a segurança alimentar; efetivação da reforma agrária e eliminação dos latifúndios; os estímulos a pequenos e médios agricultores para que recuperem a terra; a valorização da agricultura fami- 
liar quebrando, conseqüentemente, o monopólio privado das agroindústrias; políticas agrícolas voltadas à agricultura familiar; e o desenvolvimento de um amplo programa de educação para as escolas do campo.

A questão da educação do campo no Brasil sempre foi um desafio a ser vencido. Os problemas que surgem da realidade socioeconômica influenciam a concepção de educação que é oferecida aos povos do campo. Nesse sentido, a Pedagogia da Alternância a partir das EFAs (Escolas Famílias Agrícolas) vem trazer algumas reflexões acerca do tema e propor novas alternativas para que se possa efetivar uma nova práxis ${ }^{4}$ em relação à educação do campo. Desde o princípio, a educação básica do campo foi a busca de uma educação com conteúdos e metodologias específicas para a realidade do campo.

Historicamente, sabe-se que a educação do campo esteve fora da agenda política do país, ignorada e marginalizada, pois sempre esteve reduzida à escolinha rural voltada a ensinar as primeiras letras (visão utilitarista da educação), a professora desqualificada/leiga e a massas de analfabetos/as. Nunca houve interesse por parte das políticas públicas educacionais de se pensar num projeto político-pedagógico que abrangesse a realidade do campo.

Saviani (2000, p. 172) nos mostra na íntegra os documentos oficiais da educação brasileira que alertam no Art. 28 da LDB - Lei de Diretrizes e Bases da Educação Nacional (Lei n. 9 9.394/96) o seguinte propósito:

Na oferta de educação básica para a população rural, os sistemas de ensino promoverão as adaptações necessárias à sua adequação às peculiaridades da vida rural e de cada região, especialmente:

I - conteúdos curriculares e metodologias apropriadas às reais necessidades e interesses dos alunos da zona rural;

II - organização escolar própria, incluindo adequação do calendário escolar às fases do ciclo agrícola e às condições climáticas;

III - adequação à natureza do trabalho na zona rural.

O que dita o Art. 28 da $\mathrm{LDB}$ não vem sendo respeitado na maioria dos municípios que possuem realidades campesinas. Fica claro que a própria LDB possui contradições ao afirmar uma educação básica para a população rural em seu Art. 28, mas quando inicia o texto oficial ao abordar o conceito Da Educação vem dizer que a educação analisada - na LDB - se refere exclusivamente à educação escolar, visto aqui por Saviani (2000, p. 163).

A educação abrange os processos formativos que se desenvolvem na vida familiar, na convivência humana, no trabalho, nas instituições de ensino e pesquisa, nos movimentos sociais e organizações da sociedade civil e nas manifestações culturais. 
Educação do campo e escola família agrícola de Goiás: o caminhar da teimosia de um movimento...

$\S 1$. - Esta lei disciplina a educação escolar, que se desenvolve, predominantemente, por meio do ensino, em instituições próprias.

$\S 2$. - - A educação escolar deverá vincular-se ao mundo do trabalho e à prática social.

Percebe-se que o discurso da LBD afirma que a educação não acontece somente nos espaços intramuros da escolarização, mas justifica que sua abordagem será limitada somente ao espaço da educação como escola. Depois no art. 28, vem afirmar a possibilidade de uma educação básica para a população do campo sem levar em conta que na realidade campesina a educação não se dá somente nas práticas escolares, mas, principalmente, na realidade histórica e cultural de cada comunidade ou região. O que se tem aqui delineado é um grave problema de interpretação da LDB e dos discursos governamentais referentes à educação do campo e a outros tipos de educação que são reconhecidas como práticas educativas. Tais práticas, portanto, não foram objeto de reflexão da $\mathrm{LDB}$ que se limitou a perpetuar a escola como único espaço do ato de educar, fragmentalizando novamente a concepção de educação.

Qual é a educação que vem sendo oferecida ao meio rural? E qual a educação, os conceitos e os métodos utilizados na realidade camponesa? Um fato está muito transparente na realidade educacional brasileira referente às escolas do campo. Faltam políticas públicas ${ }^{5}$, princípios, concepções e métodos pedagógicos que forneçam maiores condições para se assumir uma educação específica para o campo.

Existe uma concepção simplista de educação ao se tratar dos camponeses, como por exemplo: para a escolinha rural, da roça, qualquer coisa serve ou para mexer com a enxada não precisa de muitas letras. Predomina uma imagem, histórica e ideológica, que a escolinha rural serve apenas para se aprender as primeiras letras.

A escola forma sujeitos de direitos, reconhece direitos ou nega direitos. Em sua grande maioria, ela é excludente de direitos. Os educandos são sujeitos humanos ou educandos? Qual é o olhar?

As escolas do campo, por influência do urbano, não estão reconhecendo a história concreta de cada educando/a, do coletivo, da diversidade de gêneros, das raças e das idades. Tratam o educando como número, nivela-se o conceito de educação pela média. Estando na média, passa; se não tem média, reprova e repete. Não há humanismo pedagógico. O humanismo se é que existiu foi enterrado pelo imperialismo estrutural da escola e pela burocratização das políticas públicas educativas.

Com a municipalização do ensino fundamental, aos poucos estão em processo de extinção as escolas do campo. Se antes eram poucas escolas no campo, percebe-se hoje o desaparecimento gradual das escolas isoladas rurais 
por causa da política pública educacional adotada pela maioria das prefeituras da federação. Fica complicado querer conceber políticas para escolas que não existem, mesmo as que ainda continuam a existir, atrelam-se às políticas pedagógicas do mundo urbano, ou seja, não são escolas do campo, mas escolas no campo com o modelo pedagógico do mundo urbano ${ }^{6}$ baseado na agricultura capitalista patronal.

Os camponeses estão excluídos do acesso à leitura e à escrita que é um direito fundamental e elementar de todo e qualquer cidadão. O Estado consola-se com dados de redução do analfabetismo, mas não tem um projeto político-pedagógico comprometido com a alfabetização e a pós-alfabetização.

Os movimentos sociais do campo, dentre eles, as EFAS, a CPT, o MST e as organizações indígenas ${ }^{7}$ estão lutando, na contramão da história, buscando reverter este dado que reflete a atitude real das políticas públicas municipais e estaduais adeptas a uma concepção urbana de educação.

Dentro deste quadro reflete a falta de valorização do magistério e não se tem política educacional voltada para a formação de professores/as que vivem na realidade do campo. No campo é onde se encontra uma das maiores aberrações salariais, mesmo com a lei do FUNDEF ${ }^{8}$.

Pode-se perguntar: Qual é o tipo de escola pública que vem sendo oferecida à população camponesa no Brasil e, especificamente, em Goiás? É uma escola relegada ao abandono, denominado, pejorativamente, de escolas isoladas. E, com a mudança na $\mathrm{LDB}$ que veio efetivar a municipalização do ensino fundamental, as prefeituras e as políticas desenvolvidas pelas secretarias municipais de educação, salvo raras exceções, preferem trazer as crianças, os adolescentes e os jovens para estudar na cidade ${ }^{9}$, muitas vezes em cima de caminhões de gado ${ }^{10}$ ou de kombis, em estradas precárias com horas de viagem; além de excluir as crianças do campo separando-as em salas diferentes. Estes educandos devem com isso assumir os valores da cidade, pois, senão, serão chamados de atrasados pelos colegas ou pelos próprios professores do mundo urbano.

\section{A educação do campo: um projeto político-pedagógico}

A educação básica do campo busca recriar o conceito de camponês, utilizando, portanto, a categoria campo como sinal significativo de tal recriação. A educação do campo refere-se, portanto, ao conjunto de trabalhadores/ as que habitam uma determinada realidade camponesa. Nesse sentido, abrese um grande leque de povos que podem ser denominados de povos do campo, como por exemplo: os camponeses, os quilombolas, os indígenas, os pescadores, os caiçaras, os caboclos, os bóias-frias, os seringueiros, os povos 
da floresta, os caipiras, os peões, os lavradores, os posseiros, os sem-terra, os roceiros, os sertanejos, os mineradores, os caçadores de minério (caso dos habitantes da região do Karajás - PA), todos - as pessoas simples pertencentes a uma realidade específica ${ }^{11}$.

A concepção de escola do campo procura defender os interesses, a política, a cultura e a economia da agricultura camponesa. Segundo Fernandez (1999, p. 65) “a política de educação que está sendo implantada no Brasil, por meio dos Parâmetros Curriculares Nacionais, ignora a necessidade da existência de um projeto para a escola rural". Mas, o que vem sendo um ponto agravante, é o fator regulador da qualidade de educação vista a partir de uma ótica determinista. Um determinismo geográfico que legitima a existência de uma concepção de que a escola urbana é melhor, superior do que a escola rural.

O que seria a proposta de uma educação básica do campo?

Pode-se dizer que a educação básica do campo possui três características fundamentais: é um projeto político-pedagógico da sociedade civil que busca intervir nos fundamentos da educação brasileira. Além disso, é um projeto popular alternativo para o Brasil e um projeto popular de desenvolvimento para a realidade campesina. Tais projetos estão estritamente ligados ao projeto de construção de uma política pedagógica vinculada às causas, aos desafios, aos sonhos, à história e à cultura dos povos do campo. Mas, é preciso ter bem claro que a educação do campo não é um resíduo em processo de extinção como querem alguns. É preciso ter claro, também, que a escola do campo é necessária para se cultivar a própria identidade do homem e da mulher do campo e que esta escola do campo pode vir a contribuir no desenvolvimento de estratégias de um projeto educativo socioeconômico desde que esteja contextualizada.

O processo de construção de um projeto popular alternativo de desenvolvimento para o Brasil requer novos valores éticos e culturais que precisam ser assumidos por todos. Estes valores são os compromissos básicos, urgentes e emergentes. São eles: compromisso com a soberania; com a solidariedade (extermínio da exclusão social ${ }^{12}$ e da desigualdade); com o desenvolvimento (rompimento com o capital financeiro); com a sustentabilidade; com a democracia ampliada; e, com a segurança alimentar.

Dessa maneira, pode-se formular cinco princípios básicos que mostram o papel da escola e a sua transformação. A primeira transformação do papel da escola refere-se, especificamente, a três compromissos que a educação do campo deve assumir. O compromisso ético/moral com a pessoa humana. O compromisso com a intervenção social que irá vincular os projetos de desenvolvimento regional e nacional. E, o compromisso com a cultura no seu resgate, na sua conservação e na sua recriação, tendo como eixo a educação dos valores baseada na educação para autonomia cultural a partir de Freire (1997) e na educação pela memória histórica a partir de Brandão (1985b). 
A segunda transformação do papel da escola diz respeito à gestão da escola como espaço público e comunitário, ou seja, a democratização do espaço escolar. Isto significa que deve haver ampliação (quantitativa e qualitativa) do acesso às escolas; participação da comunidade nas decisões sobre gestão escolar, propostas pedagógicas e políticas públicas; participação dos educandos/as na gestão escolar superando a democracia representativa ${ }^{13}$; e, a criação de coletivos pedagógicos que pensem e repensem os processos de transformação. Assim diz a educadora Roseli Salete Caldart (1997, p. 45), do Setor Educação do MST, a respeito dos coletivos pedagógicos:

Uma das lições da nossa prática é a de que a transformação da escola não acontece sem a constituição de coletivos de educadores. Um educador ou educadora que trabalhe sozinho/a, jamais conseguirá realizar esta proposta de educação, até porque isso seria incoerente com o processo coletivo que a vem formulando. São precisos coletivos para pensar a continuidade da luta por escolas em condições adequadas, para organizar a Equipe de Educação do assentamento ou acampamento, para planejar formas de implementação das mudanças no currículo, para refletir sobre o processo pedagógico, para estudar, para planejar e avaliar as aulas, para continuar sonhando e recriando esta proposta. Em cada local o desafio é o de encontrar a melhor forma de constituir e fazer funcionar estes coletivos.

A terceira transformação do papel da escola vem abordar a pedagogia escolar, na qual a educação popular será inserida no cotidiano escolar e no processo de ensino-aprendizagem. A finalidade dessa transformação é trazer, para a escola, alternativas pedagógicas que são produzidas fora do espaço escolar formal; analisar as experiências e as discussões que acontecem a respeito da renovação pedagógica; aprender a conhecer, aprender a viver juntos, aprender a fazer e aprender a ser ${ }^{14}$.

A quarta transformação refere-se aos currículos escolares que devem se adequar no movimento da realidade que o cerca. Por isso, a princípio, deve-se retirar o conceito de que a escola é mera transmissora de conhecimentos teóricos. Mas é um espaço, por excelência, de formação humana. Para isso, faz-se necessário pensar um novo ambiente educativo. Num segundo momento, refletir sobre a existência do reducionismo de tendência pedagógica em ter a escola como simples espaço de memorização e de informação. Posteriormente, exigir que o currículo de uma escola do campo contemple as relações com o trabalho na terra e trabalhar o vínculo entre educação e cultura, sendo a escola um espaço de desenvolvimento cultural de toda a comunidade. E, por fim, o currículo deve romper com a postura presenteísta que domina nossa sociedade ${ }^{15}$.

Enfim, a quinta transformação do papel da escola vem mostrar a (trans)formação dos educadores e educadoras das escolas do campo. Dois 
Educação do campo e escola família agrícola de Goiás: o caminhar da teimosia de um movimento...

problemas são visíveis: os educadores são vítimas de um sistema educacional que desvaloriza o trabalho da docência e, principalmente, os coloca num círculo vicioso e perverso. Isso faz gerar uma conseqüência problemática: como vítimas (os educadores/as) constroem novas vítimas, os educandos/as das escolas do campo. As iniciativas específicas para educadores/as do campo são: articulação, ou seja, a criação e o fortalecimento dos coletivos pedagógicos locais, municipais, estaduais, nacionais e internacionais; qualificação ou formação escolar para os docentes leigos/as; e, criar programas sistemáticos de formação com metodologias pedagógicas alternativas e dialógicas.

\section{EFA: um movimento social educa tivo}

Existem alternativas sendo desenvolvidas pelas organizações e pelos movimentos sociais que tentam solucionar os problemas das escolas do campo ao construir projetos alternativos, como, por exemplo, é o caso: das Escolas Família-Agrícola (EFAs), dentre elas, a Escola Família Agrícola de Goiás (EFAGO) que busca oferecer aos camponeses uma educação vinculada à cultura da região a partir da Pedagogia da Alternância, ou seja, valoriza-se o tempo escola e o tempo comunidade-família ${ }^{16}$. As EFAs, em seus princípios, procura estimular a agricultura familiar, numa perspectiva comunitária, na busca de diversificação e de alternativas adequadas à preservação da vida e do meio ambiente e contribuir com as iniciativas dos trabalhadores na conquista de uma política agrícola diferenciada para este setor. Além de valorizar, incentivar e promover o intercâmbio das experiências alternativas de organização, de gerenciamento da produção, do beneficiamento (agregando valores) e da comercialização, visando a garantir a qualidade do produto, o acesso ao mercado e uma renda justa.

Sabe-se que a educação rural oferecida no Brasil e em Goiás aos camponeses demonstra sérios problemas que deverão, nestes próximos anos, estar sendo refletidos com mais responsabilidade pelas políticas públicas de educação bem como pelos educadores que estão imersos na realidade socioeducativa do mundo rural. No entanto, percebe-se de um modo geral que as escolas que existem no campo possuem problemas como: docentes que são desqualificados com visão de mundo urbano ou visão de agricultura patronal ${ }^{17}$, falta renovação pedagógica, currículo e calendário alheio à realidade do campo, falta de formação específica para os educadores, políticas que apresentam o urbano como superior, o deslocamento dos educandos para estudar na cidade e a desqualificação do campo feito pelas políticas públicas.

Dentro desta perspectiva, a EFAGO pode ser considerada com um dos paradigmas que busca, por meio de ações coletivas ${ }^{18}$, ser um movimento social 
educativo que caminha na contramão da história dominante que possui o financiamento, as políticas públicas, o poder, a gestão (de cima para baixo), os curńculos e a pedagogia. Por isso, a Escola Família Agrícola de Goiás busca realizar um processo de efetivar parcerias/convênios com as Secretarias Estaduais e Municipais de Educação, a fim recriar as escolas do campo a partir da cultura local.

A Educação Básica do Campo não pode ser vista sem a participação do movimento social existente no campo. É a partir das pedagogias, dentre elas, a Pedagogia da Alternância, construídas pelo movimento, que poderá ser compreendido o fenômeno educativo camponês. A pedagogia dos gestos, do fazer, da construção coletiva, fala mais do que qualquer teoria pedagógica pensada pelo cientificismo das estruturas educacionais. A característica do movimento social é exatamente falar pelos gestos, ou seja, falar por meio da linguagem, das palavras, dos rituais, da mística. Isso pode ser percebido claramente nos encontros e nas ações coletivas, por exemplo, da Escola Família Agrícola de Goiás.

Para Arroyo (1999, p. 09)

(...) os movimentos sociais são em si mesmos educativos em seu modo de se expressar, pois o fazem mais do que por palavras, utilizando gestos, mobilizações, realizando ações, a partir das causas sociais geradoras de processos participativos e mobilizadores.

Nesse sentido, o movimento social do campo existe, está em movimento, inquieto. Há um movimento pedagógico do campo de renovação a partir das propostas elaboradas pelos movimentos sociais do campo, sejam os sem-terra, os povos indígenas, os pescadores (caiçaras), os lavradores, seringueiros etc. E, há uma outra renovação sendo construída a partir das propostas dos governos populares, principalmente, pelos municípios e estados governados pelo PT (Partido dos Trabalhadores) ${ }^{19}$. A Educação se dá nesta realidade do campo e dos movimentos sociais nos quais determinante e determinado se constroem a partir da relação dialética existente entre o contexto real (realidade do mundo rural) e o contexto ideal (utopia dos movimentos sociais do campo). Por isso, os movimentos sociais são educativos, por excelência, pois formam novos valores, nova cultura.

Assim, se não houvesse um movimento social do campo não se estaria construindo uma educação básica do campo. Por isso, nada mais justo afirmar que a Escola Família Agrícola de Goiás, em sua ousadia de buscar realizar uma proposta de educação diferenciada e alternativa para o município de Goiás, possa ser considerada um movimento social educativo, pois busca construir cidadania, historicamente, negada aos camponeses.

O objetivo principal da EFAGO, além o de educar e aprender, é "recolocar o rural e a educação que a ele se vincula, na agenda política do 
país" (1998, p. 22) e o desafio é o de "pensar e fazer uma educação vinculada às estratégias de desenvolvimento" (1998, p.23). O intuito é o de incluir ${ }^{20}$ na pauta de reflexão do PNE (Plano Nacional de Educação) a proposta de se fomentar uma educação básica do campo. Por isso, a EFA é interpelada a construir um ideário pedagógico que nunca se feche em si mesmo, nem mesmo se torne pronto e acabado. Precisa-se pensar a escola do campo como movimento de transformação da realidade.

$O$ tesouro da EFAGO e das EFAs espalhadas pelo Brasil são os instrumentos pedagógicos da Alternância. Na verdade, a EFAGO e as EFAs realizam a educação nas três dimensões possíveis, que são: a educação formal (escola), a educação não-formal (práticas educativas realizadas na comunidade e na sociedade) e a educação informal (família).

Segundo Gohn (2001, p. 100), a família é caracterizada como espaço de educação informal que acontece "nos processos espontâneos ou naturais, ainda que seja carregada de valores e representações, como é o caso da educação familiar". A educação não formal se dá na "intencionalidade de dados sujeitos em criar ou buscar determinadas qualidades e/ou objetivos". Nesse sentido, a educação não formal está presente no bairro-associação, nas organizações, nos movimentos sociais, nas igrejas, nos sindicatos, nos partidos políticos e nas ONGs.

A EFAGO, em teoria, é um projeto de renovação pedagógica cuja caracterização se dá por falar mediante gestos, símbolos (rituais, músicas, danças e teatros) e linguagens próprias da cultura camponesa. Contrapondo-se, assim, às atuais dimensões educativas com matrizes pedagógicas esquecidas pelo predomínio da pedagogia da fala, da transmissão, do discurso do mestre para alunos/as silenciosos(as), seja no mundo urbano ou rural. Este é mais um desafio a ser realizado em caráter de urgência porque, caso contrário, a Escola Família Agrícola de Goiás cairá nos mesmos problemas existentes nas escolas rurais de Goiás, a saber: uma concepção de educação brasileira baseada no urbanocentrismo (a cidade), no sociocentrismo (interesse de classes) e no etnocentrismo (pensamento ocidental) como sendo os únicos paradigmas possíveis.

A educação camponesa se constrói a partir de um movimento sociocultural de humanização, visto que sua centralidade encontra-se na busca pela pedagogia do ritual, do gesto, do corpo, da representação, da comemoração e do fazer memória coletiva. As pessoas, gente do campo, tornam-se sujeitos culturais, celebrando sua memória ao resgatar a identidade por meio da educação.

Quando se pensa a educação do campo torna-se imprescindível dizer que ela é chamada a construir matrizes humanistas tendo em vista a emancipação humana. Nesse sentido, a educação do campo pensada pelas EFAs se 
diferencia da educação formal. Na educação do campo a partir das EFAs todos são sujeitos e construtores da memória e da história. Eles são sujeitos sociais e culturais. Já na educação formal o visível é o reducionismo dos alunos a aprovados/reprovados, novatos/repetentes, defasados especiais/anormais, além de criar um grande dualismo entre educador e educando.

Há uma grande possibilidade de se abrir um leque de temas transversais na educação do campo que podem e devem ser recuperados em todas as unidades escolares e em suas respectivas comunidades, como por exemplo: a esperança, cidadania, justiça, liberdade, igualdade, sexualidade, cooperação, diversidade, terra, trabalho, identidade ${ }^{21}$... Por isso, fica evidenciado o caráter específico, diferenciado e alternativo da educação do campo proposto pela Escola Família Agrícola de Goiás, mesmo tendo a certeza de que se precise superar suas próprias contradições.

\section{Conclusão}

Os desafios são históricos e pode-se dizer que estão em caminhada. O compromisso com a escola do campo é um compromisso que integra a luta brasileira por uma educação básica, de qualidade, onde se pretende ampliar a educação (tempo-oportunidade) para o povo brasileiro. Além disso, pretendese realizar a transformação da escola (que escola temos e que escola queremos). Inventar novas alternativas pedagógicas que venham substituir as velhas práticas educacionais ultrapassadas que até hoje estão "mofando" nas unidades escolares e, principalmente, no sistema estrutural de ensino. Dessa maneira, se estará construindo a verdadeira educação para a autonomia.

Precisa-se recuperar os vínculos entre educação e terra, educação e trabalho (cf. Pistrak, 1981), educação e produção, educação e vida, educação e cotidiano da existência. Dessa maneira, a EFAGO é mais um elemento que faz com que haja educação do campo. Os processos educativos acontecem fundamentalmente nos movimentos sociais, nas lutas, no trabalho, na produção, na família e na vivência cotidiana. Nesse sentido, qual é a função da escola? Para Arroyo (1999, p. 27), a escola deve

interpretar esses processos educativos que acontecem fora, fazer uma síntese, organizar esses processos educativos em um projeto pedagógico, organizar o conhecimento, socializar o saber e a cultura historicamente produzidos, dar instrumentos científicos técnicos para interpretar e intervir na realidade, na produção e na sociedade.

Vê-se a necessidade de abrir e ampliar o debate acerca desta propos- 
ta com outros organismos que podem oferecer reflexões sérias e pertinentes em relação a um tema historicamente complexo como é o caso da educação do campo. Entidades como o Congresso Nacional de Educação (CONED), a Associação Nacional de Pós-Graduação e Pesquisa na Educação (ANPED) e a Federação Nacional dos Trabalhadores em Educação (CNTE) poderão servir como espaços para a reflexão democrática acerca de novas alternativas que venham a construir futuros projetos político-pedagógicos como o das EFAs, dentre elas, a Escola Família Agrícola de Goiás, destinados a atender a população a qual se vincula a educação camponesa.

\section{Notas}

1 O tema do projeto de pesquisa da Dissertação do Mestrado em Educação é: A EDUCAÇÃO CAMPONESA COMO ESPAÇO DE RESISTÊNCIA E RECRIAÇÃO DA CULTURA: UM ESTUDO SOBRE AS CONCEPÇÕES E PRÁTICAS EDUCATIVAS DA ESCOLA FAMÍLA AGRÍCOLA DE GOIÁS. Unicamp, 2002. 23p. (mimeo.). Orientadora: Prof. a Dra. Maria da Glória Marcondes Gohn.

2 Grifo nosso. Autor desconhecido.

3 Modo de Produção é um processo complexo que envolve a forma de organização do processo de trabalho, a relação existente entre as classes sociais naquele processo (segundo sua posição: proprietários dos meios de produção - a burguesia, - ou força de trabalho - os trabalhadores/as); e a divisão de trabalho que se estabelece entre as classes sociais na sociedade. Cada época histórica apresenta um tipo de divisão do trabalho e um modo de produção. Marx (1968) e (1974) estudou o modo de produção antigo (Roma e Grécia), o modo de produção feudal e o modo de produção capitalista.

4 Práxis é um conceito que foi bastante desenvolvido por autores marxistas como Kossik (1976), Gramsci (1981) e Luckács (1971) e não deve ser confundido com o de prática. Ele envolve um pensar e um fazer constante.

5 Entende-se por políticas públicas os conjuntos de ações resultantes do processo de institucionalização de demandas coletivas, constituído pela interação Estado-sociedade.

6 É preciso salientar, no que se refere ao mundo urbano, que se têm delineado, ao longo da história, processos educativos que se apresentam como alternativos, populares e democráticos que, também, possuem limites e críticas, mas foram e estão sendo verdadeiros espaços de construção do saber e de reconstrução da cultura, como por exemplo: a Escola Plural (Minas Gerais), a Escola Cidadã (Instituto Paulo Freire em São Paulo e Centro Paulo Freire no Nordeste, principalmente, em Recife), a Escola Candanga (Brasília) e outras experiências isoladas de prefeituras que se esforçam por implantar uma educação escolar ligada a uma educação que se faz na cultura, segundo a concepção de Brandão (1985a), no cotidiano das pessoas, nas festas, na religiosidade e em outras dimensões.

7 CNBB. Texto Base da Campanha da Fraternidade 2002. pp. 54-56. Trata especificamente da recriação de escolas que respeitem o jeito de ser indígena.

8 Fundo de Manutenção e Desenvolvimento do Ensino Fundamental e Valorização do Magistério.

9 No Estado de Goiás, com a municipalização do ensino fundamental, as prefeituras adotaram esta política de redução de gastos. No município de Goiás, há uma política direcionada para implantar em todo o município o transporte das crianças e adolescentes do campo para estudar na cidade de Goiás, inclusive, as crianças e adolescentes dos assentamentos. 
10 Em 2000, na cidade de Fazenda Nova - GO, a Secretaria Municipal de Educação adotou esta política. Trazia as pessoas do Assentamento Nossa Senhora de Fátima para a cidade, misturando crianças da escola e os adultos, em um ônibus que não tinha nenhuma condição, pessoas literalmente amontoadas como gado.

11 Deve-se tomar cuidado com esta palavra. Emprego o termo simples para mostrar que a população camponesa não busca viver de maneira individualista, ao contrário, vivem na simplicidade porque sabem partilhar a terra e são, em sua grande maioria, pessoas solidárias. Muitas vezes, na história do Brasil, as palavras simples ou simplicidade foi usada ideologicamente pelas elites oligárquicas, fazendo com que negros, índios, caboclos e camponeses se tornassem submissos, "bonzinhos", humildes... Dessa maneira foram enganados e desrespeitados em seus direitos.

12 Segundo Gohn (1999, p. 40) a exclusão social designa um processo de não integração no sistema da sociedade regida por relações contratuais lastreadas no pagamento do trabalho dos indivíduos segundo determinadas leis. Os indivíduos passam a ter inserções pontuais no mercado de trabalho segundo políticas sociais de caráter assistencialistas. Castel (1998) prefere denominar o processo de exclusão de desfiliação.

13 Na EFAGO, a Gestão realiza-se a partir da Associação de Pais e Alunos. Todos os pais, alunos/as e monitores/as são chamados a participar das decisões que envolvem o funcionamento administrativo e pedagógico da escola. Mesmo assim, ainda se tem a concepção de uma democracia representativa em face da necessidade de formar uma conscientização que leve à construção de uma democracia socioparticipativa.

14 Estes quatro tópicos a respeito do ato de conhecer foram abordados no Relatório para a UNESCO da Comissão Internacional sobre Educação para o século XXI. Cf. DELORS, Jacques (Org.). Educação: um tesouro a descobrir. São Paulo, Cortez; Brasília, MEC: UNESCO, 2000. p. 20.

15 CHASSOT, Attico. Presenteísmo: uma conspiração contra o passado que ameaça o futuro. Unijuí, 1998. O que inspirou o autor a analisar este tema dentro do MST foi o historiador Hobsbawm. Cf. HOBSBAWM, Eric. Era dos Extremos. São Paulo, Companhia das Letras, 1995. p. 13.

16 A Pedagogia da Alternância vem sendo trabalhada há mais de 30 anos pelas Escolas Famílias Agrícolas (EFAs).

17 As observações realizadas demonstram que alguns monitores da EFAGO precisam de maior formação e entendimento sobre a Pedagogia da Alternância e de seus respectivos instrumentos pedagógicos. Há uma espécie de duas dimensões no universo das representações desses educadores. A priori revelam concordar com a proposta pedagógica da EFA, mas se houver uma observação mais aprofundada, poderá ser percebido um descompromisso e uma postura de não engajamento. Por exemplo: de uns tempos para cá a Visita às Famílias vem sendo feita somente na comunidade em forma de palestras, pelos monitores da área técnica. A ficha das visitas há um ano não vem sendo preenchida, sendo que tais informações poderiam contribuir para uma melhor compreensão da realidade socioeconômica, cultural, política e religiosa das famílias e do principal agente da educação, a saber: os educandos.

18 Segundo Gohn (1999, p. 43) ação coletiva é um conceito das Ciências Sociais, especialmente, na abordagem de Weber (1969) - onde a ação social é a referência básica para o entendimento da sociedade. Na prática, a ação social se traduz em inúmeras formas de ações coletivas - seja no plano econômico, social, político e cultural.

19 Isto não significa que propostas de outros partidos não existam. Apenas quero levantar um fato que é visível em nossa atual conjuntura política. Aonde o PT vem governando, principalmente, nas pequenas e médias cidades, há um trabalho intenso de renovação pedagógica voltado para a descentralização do poder e de abertura a uma efetivação da gestão democrática dentro das estruturas de organização do sistema educacional.

20 A inclusão social pode se efetivar a partir da educação, mas não somente pela educação. A educação 
Educação do campo e escola família agrícola de Goiás: o caminhar da teimosia de um movimento...

deve estar presente no debate conjunto de ações políticas, econômicas e culturais. Deve-se tomar cuidado para não se cair na falácia histórica a respeito da educação que por si só não pode impedir o êxodo rural e muito menos a concentração da propriedade privada. Cometer-se-ia, novamente, uma falácia ao indicar a educação como salvadora dos problemas sociais existentes. Seria atribuir à educação um papel extremamente redentor que irá solucionar todos os males da humanidade.

21 A questão da identidade é um dos problemas existentes dentro do universo cotidiano da EFAGO. Existe uma espécie de rivalidade ideológica entre os que não são assentados com aqueles que são assentados. O discurso é estritamente ideológico proveniente da mídia televisiva. Por exemplo: Não somos posseiros... Não invadimos terra... Não somos baderneiros... Enfim, possuem uma consciência de que ser posseiro é pertencer a uma classe social inferior, espécies de anarquistas.

\section{Referências}

ARROYO, Miguel G. Educação Básica e Movimentos Sociais. In: VV.AA. A educação básica e o movimento social do campo. Brasília: UnB, 1999. p. 15-52.

BRANDÃO, Carlos Rodrigues. A Educação como Cultura. 2 ed. São Paulo: Brasiliense, 1985a.

\section{meiros Passos)}

. O que é educação. São Paulo: Brasiliense, 1985b. (Coleção Pri-

CALDART, Roseli Salete. Educação em Movimento: formação de educadoras e educadores no MST. Petrópolis: Vozes, 1997.

CASTEL, R. As metamorfoses da questão social: uma crônica do salário. Petrópolis: Vozes, 1998.

CHASSOT, Attico. Presenteísmo: uma conspiração contra o passado que ameaça o futuro. Unijuí, 1998 (mimeo.).

IGREJA CATÓLICA; CNBB. Texto Base da Campanha da Fraternidade. Brasília: CNBB, 1998. p. 55-134. . Brasília: CNBB, 2002. p. 07-111.

DELORS, Jacques. Educação: um tesouro a descobrir. relatório para a UNESCO da Comissão Internacional sobre Educação para o séc. XXI. 4 ed. São Paulo: Cortez, 2000.

FERNANDEZ, Bernardo Mançano. Por uma educação do campo. In: VV.AA. A educação básica e o movimento social do campo. Brasília: UnB, 1999. p. 53-70. 
FREIRE, Paulo. Pedagogia do Oprimido. 17 ed. Rio de Janeiro: Paz e Terra, 1987.

GOHN, Maria da Glória. Classes Sociais e Movimentos Sociais. In: REPRODUÇÃO Social, Trabalho e Serviço Social. Brasília: UnB, 1999. p. 36-54.

Cortez, 2001.

.Educação Não-Formal e Cultura Política. 2. ed. São Paulo:

GRAMSCI, A. A concepção dialética da história. 4. ed. Rio de Janeiro: Civilização Brasileira, 1981.

HOBSBAWM, Eric. Era dos Extremos: o breve século XX. São Paulo: UNESP, 1995.

KOSSIK, K. Dialética do Concreto. 2. ed. Rio de Janeiro: Paz e Terra, 1976.

LAMARCHE, H. (Coord.). A agricultura familiar. Campinas: Editora da Unicamp, 1993.

LISITA, Cyro. Latifondiaires, violence et pouvoir: les relations avec la paysannerie e l'église dans l'État de Goias-Brésil. Paris, 1992. Thése (Doctorat em Sociologie) - Ecole des Hautes Etudes em Sciences Sociales.

LUCKÁCS, G. History and class consciousness. Londres: Merlin Press, 1971.

MARTINS, José de Souza. Capitalismo e Tradicionalismo. São Paulo: Biblioteca Pioneira de Ciências Sociais, 1975.

MARX, K. Manifesto do Partido Comunista. São Paulo: Escriba, 1968.

. O Capital.. Rio de Janeiro: Civilização Brasileira, 1974. Livro III

MEC. Lei de Diretrizes e Bases da Educação Nacional: Lei n. o 9394/96. Brasília: MEC. 1996.

PISTRAK. Fundamentos da escola do trabalho. São Paulo: Brasiliense, 1981.

SAVIANI, Demerval. A Nova Lei da Educação, LDB: trajetórias, limites e perspectivas. 6 ed. rev. Campinas: Autores Associados, 2000.

VV.AA. Por uma educação básica do Campo: texto-base da Conferência Nacional. Brasília: UnB, 1998.

1999.

. A educação básica e o movimento social do campo. Brasília: UnB, 
. Projeto Popular e escolas do campo. Brasília, UnB, 2000.

WANDERLEY, Maria de Nazareth Baudel. O "lugar" dos rurais: o meio rural no Brasil moderno. In: CONGRESSO DA SOCIEDADE BRASILEIRA DE ECONOMA E SOCIOLOGIA, 35. , Brasília, 1997. Anais.... Brasília: SOBER, [1997.

Recebido em: 18/12/2002

Aprovado em: 8/2/2003 